\section{Myositis in a child with murine typhus}

\author{
Sheshashree Seshadri, Jaime Fergie \\ Pediatric Infectious Disease, Driscoll \\ Children's Hospital, Corpus Christi, TX, \\ USA
}

\section{Abstract}

A 12-year-old boy presented with fever, lower extremity pain and weakness. Examination revealed paraparesis, thigh and calf tenderness. Labs showed high creatinine phosphokinase and Rickettsia typhi titers. This case illustrates endemic typhus should be considered in the differential diagnosis of myositis especially in areas with high prevalence of the disease. To our knowledge, this is the first reported case of myositis and paraparesis associated with a case of murine typhus.

\section{Introduction}

Myositis is an acute, sub-acute, or chronic inflammation of skeletal muscles. Myositis can be due to infectious or non-infectious etiologies. Influenza is the most common cause of infectious myositis. ${ }^{1-3}$ Infectious myositis caused by Rickettsia typhi has not been reported widely in the literature.

\section{Case Report}

A previously healthy 12 -year-old boy was admitted to Driscoll Children's Hospital in Corpus Christi, TX, USA, with a 9 day history of fever, and 7 day history of pain and weakness in the lower extremities. Three days prior to admission, he was seen by a nurse practitioner and diagnosed with otitis media and pharyngitis. He received intramuscular penicillin and was prescribed cefixime for 3 days without improvement. He progressed and he became unable to walk without assistance. He had no gastrointestinal, respiratory or genitourinary complaints. On admission, his temperature was $36.8^{\circ} \mathrm{C}$ and the physical examination was significant for antalgic, broad-based gait and tender gastrocnemius - soleus muscles. Biceps, quadriceps and psoas muscle strength was graded at $3 / 5$. Sensation and deep tendon reflexes were normal with absent Romberg's and Babinski's sign. The white blood cell count was 8300 cells per cubic mm with $60 \%$ neu- trophils and 40\% lymphocytes, hemoglobin was $13.5 \mathrm{~g} / \mathrm{dL}$, and the platelet count was 172,000 cells per cubic mm. His CRP was $1.5 \mathrm{mg} / \mathrm{dL}$. The ESR and urine analysis were normal. Creatinine phosphokinase (CPK) was elevated at $2394 \mu / \mathrm{L}$, aspartate aminotransferase (AST) was $222 \mu / \mathrm{L}$ and, alanine aminotransferase (ALT) was $143 \mu / \mathrm{L}$.

A diagnosis of myositis was made and the patient was given analgesics and oral prednisone as dermatomyositis and polymyositis were amongst the differential diagnosis. Rhabdomyolysis was considered in the differential diagnosis and the patient was started on one and a half maintenance intravenous fluids. He did not have dark urine or hyperkalemia or myoglobinuria or renal failure. Our patient's clinical course was not severe and did not develop the complications usually associated with rhabdomyolysis. On day 2 of his hospital stay, he was able to stand up with support and CPK levels came down to $1713 \mathrm{U} / \mathrm{L}$. Cerebrospinal fluid analysis showed a protein concentration of $62 \mathrm{mg} / \mathrm{dL}$ and white blood cell count of 4 . Electromyography and nerve conduction studies did not show evidence of Guillain Barre Syndrome. A multiplex respiratory viral PCR was positive for rhinovirus and negative for Influenza A and B, parainfluenza, metapneumovirus and adenovirus. Lyme disease serology and monospot for Epstein Barr Virus were reported negative. Arboviral titers for West Nile virus was negative and so was the Rocky Mountain spotted fever titers. On the day 3 of his hospitalization, his upper extremity strength significantly improved to $5 / 5$ and lower extremity to $4 / 5$. Hence he was able to sit up and walk down the hallway without support. Rickettsia typhi IgM was elevated at 512 and IgG at 1024 . Serum was evaluated by use of an indirect immunofluorescence antibody (IFA) test kit for immunoglobulin G (IgG) to Rickettsia typhi and Rickettsia rickettsii (Focus Diagnostics, Cypress, CA, USA). Reciprocal titers $>64$ were considered positive. CPK, ALT and AST levels were noted to have a downward trend. Blood and cerebrospinal fluid cultures showed no growth. The complete recovery of the patient took about 48 hours which included $100 \mathrm{mg}$ of doxycycline given twice daily by mouth. He was discharged home on doxycycline to complete a 10 day course and prednisone was discontinued.

\section{Discussion}

Myositis can be caused by strenuous activity, muscle trauma, illicit drug injections, genetic diseases, connective tissue disorders, diabetes and infections. ${ }^{4,5}$ Infectious myositis can involve single or multiple muscle groups in
Correspondence: Sheshashree Seshadri, Driscol Children's Hospital, 3533 S. Alameda St., Corpus Christi, TX 78411, USA

Tel. +1.361.946.4641 - Fax: +1.915.598.3946

E-mail: strongwinner@gmail.com

Key words: Rickettsia, myositis, murine typhus, pediatric.

Contributions: SS, primary author; JF, Infectious Disease specialist, secondary author.

Conflict of interests: the authors declare no potential conflict of interests.

Received for publication: 30 0ctober 2013.

Revision received: 16 November 2013.

Accepted for publication: 6 December 2013.

This work is licensed under a Creative Commons Attribution NonCommercial 3.0 License (CC BYNC 3.0).

(C) Copyright S. Seshadri and J. Fergie, 2014

Licensee PAGEPress, Italy

Infectious Disease Reports 2014; 6:5145

doi:10.4081/idr.2014.5145

the limbs with the proximal muscles being predominantly affected the exception being trichinosis which commonly involves orbital muscles. ${ }^{4}$ Infectious myositis is more frequently seen in young adults and has a male predilection. ${ }^{4}$

Signs and symptoms of myositis include fever, malaise, muscle swelling, weakness and pain that is worse with movement. With this presentation, other diseases that should be considered are polymyositis, dermatomyositis, rhabdomyolysis, Guillain Barre Syndrome, cellulitis, osteomyelitis, deep vein thrombosis, metabolic and other inflammatory myopathies (Table 1). ${ }^{4}$ Rhabdomyolysis was considered as one of the top differential diagnosis for our patient and given intravenous fluids. He had a mild manifestation of rhabdomyolysis. He did not have myoglobinuria or show signs of renal failure.

Murine typhus is an infectious illness caused by Rickettsia typhi. It presents 1-2 weeks after the bite of an infected flea although a history of such exposure is rarely elicited. ${ }^{6}$ Symptoms of murine typhus include fever, severe headache and rash. The rash may not be present in $50 \%$ of the patients with murine typhus. ${ }^{4}$ Rats, opossums, cats and dogs can serve as hosts. ${ }^{5}$ Doxycycline is the treatment of choice, ${ }^{5}$ which our patient was prescribed at the time of discharge. It has been known that murine typhus resolves even without treatment. ${ }^{\text {? }}$

To our knowledge, this is the first pediatric case reported of Murine typhus associated with myositis and paraparesis. 
Table 1. Reported causes of infectious myositis.

\begin{tabular}{ll}
\hline Viruses & Group B coxsackievirus (epidemic myalgia) \\
& HIV-1 (one of the most common causes of myositis) \\
& Influenza (benign acute childhood myositis) \\
Bacteria & Escherichia coli \\
& Klebsiella pneumoniae \\
& Pseudomonas aeruginosa \\
& Staphylococcus aureus (most common, 70\%) \\
& Streptococcus viridans \\
& Streptococcus pyogenes \\
& Streptococcus pneumoniae \\
& Borrelia burgdorferi \\
Spirochetal & Mycobacterium avium-intracellulare complex \\
Mycobacterial & Echinococcus granulosus \\
\hline Parasitic & Taenia solium \\
& Toxoplasma gondii \\
& Trichinella spiralis \\
Fungus & Aspergillus species \\
& Candida species \\
& Coccidioides species \\
& Cryptococcus neoformans \\
& Histoplasma capsulatum
\end{tabular}

\section{Conclusions}

Murine typhus continues to occur frequently in South Texas children. ${ }^{8}$ Physicians practicing in or near Rickettsia typhi-endemic areas need to consider this in the differential diagnosis of children with evidence of myositis. ${ }^{9}$ Making this diagnosis may have a significant impact on the course of the disease because of the availability of antimicrobial therapy against rickettsial organism. ${ }^{5}$

\section{References}

1. Committee on Infectious Diseases.
Prevention of influenza: recommendations for influenza immunization of children. Pediatrics 2008;121:e1016-31.

2. Dietzman DE, Schaller JG, Ray CG, Reed ME. Acute myositis associated with influenza B infection. Pediatrics 1976;57:255-8.

3. Massung RF, Davis LE, Slater K, et al. Epidemic typhus meningitis in the southwestern United States. Clin Infect Dis 2001;32:979-82.

4. Zafar MJ. Infectious myositis. Available from: http://emedicine.medscape.com/article/1168167

5. AAP Committee on Infectious Diseases. Endemic typhus (murine typhus). In: Pickering LK, ed. Red book 2012: 2012 report of the Committee on Infectious Diseases. 29th ed. Elk Grove Village: American Academy of Pediatrics; 2012. pp 710-711

6. Adjemian J, Parks S, McElroy K, et al. Murine typhus in Austin, Texas, USA, 2008. Emerg Infect Dis 2010;16:412-7.

7. Fergie JE, Purcell K, Wanat D. Murine typhus in South Texas Children. Pediatr Infect Dis J 2000;19;535-8.

8. Purcell K, Fergie J, Richman K, et al. Murine typhus in children, South Texas. Emerg Infect Dis 2007;13:926-7.

9. Linneman CC Jr, Pretzman CI, Peterson ED. Acute febrile cerebrovasculitis. A nonspotted fever group rickettsial disease. Arch Intern Med 1989;149:1682-4. 